\title{
Botanicals and Herbs: A Traditional Approach to Treating Epilepsy
}

\author{
Steven C. Schachter \\ Department of Neurology, Beth Israel Deaconess Medical Center, Harvard Medical School, Boston, Massachusetts 02215
}

\begin{abstract}
Summary: Botanicals and herbs have a centuries-old tradition of use by persons with epilepsy, in many cultures around the world. At present, herbal therapies are tried by patients in developing as well as developed countries for control of seizures or adverse effects from antiepileptic drugs (AEDs), or for general health maintenance, usually without the knowledge of physicians who prescribe their AEDs. Well-designed clinical trials of herbal therapies in patients with epilepsy are scarce, and methodological issues prevent any conclusions of their efficacy or safety in this population. Furthermore, some botanicals and herbs may be proconvulsant or may alter AED metabolism. In spite of these limitations, further preclinical eval-
\end{abstract}

uation of botanicals and herbs and their constituent compounds using validated scientific methods is warranted based on numerous anecdotal observations of clinical benefit in patients with epilepsy and published reports showing mechanisms of action relevant to epilepsy or anticonvulsant effects in animal models of epilepsy. This review highlights the use of herbal therapies for epilepsy, outlines the role of the U.S. Food and Drug Administration in regulating herbal products, and presents the author's approach to the scientific assessment of herbal therapies as potential therapies for patients with epilepsy. Key Words: Epilepsy, herbal medicine, botanical, dietary supplement, complementary and alternative therapies, huperzine A.

\section{INTRODUCTION}

Despite the availability of many antiepileptic drugs (AEDs), nearly one in three patients with epilepsy who have access to AEDs continue to have seizures, and a similar proportion experience unacceptable AED-related adverse effects. ${ }^{1}$ In addition, the large majority of people with epilepsy around the world are not under treatment with AEDs, largely because of their lack of access to physicians, the costs of AEDs, and cultural attitudes toward modern treatments. ${ }^{2}$

Over thousands of years, people with epilepsy have used a variety of botanicals and herbs, hereafter referred to simply as herbal therapies (although no clinical benefit is implied by this term). Today, herbal therapies are among the most commonly used forms of complementary and alternative medical (CAM) therapies by patients. The National Institutes of Health-National Center of Complementary and Alternative Medicine (NIH-NCCAM; http://nccam.nih.gov/) identifies CAM therapies as health-

Address correspondence and reprint requests to: Steven C. Schachter, M.D., 330 Brookline Avenue, K-478, Boston, MA 02215.

E-mail: sschacht@ caregroup.harvard.edu. care and medical practices that are not currently an integral part of conventional medicine-meaning the system of medical knowledge and practices taught in Western medical schools (for example, in the United States), and as practiced by Western-trained physicians, including neurologists.

Patients with a variety chronic illnesses, including epilepsy, take herbal therapies for many reasons. For example, patients in developed countries may view herbal therapies as natural and time-tested and therefore safe compared with what are perceived as artificial drugs-an attitude supported by recent reports of safety concerns associated with widely prescribed FDA-approved drugs. In developing countries, there may be access to herbal therapies but not to pharmaceuticals, because of cultural and economic factors.

Herbal traditions include traditional Chinese medicine, Ayurveda, and other culturally specific practices in which plant materials, processed or not, are ingested by persons with the intention of reducing symptoms or curing disease. This review focuses on the extent and patterns of use of herbal therapies by patients with epilepsy, regulatory considerations for dietary supplements (which include herbal therapies in the United States), safety issues, specific herbal therapies that have been used and evalu- 
ated for epilepsy, and a bench-to-bedside approach to herbal therapy research for epilepsy.

\section{Extent and patterns of use}

Developed countries. In developed countries, CAM treatments, including herbal therapies, are often used for general health maintenance or for chronic conditions, such as pain or epilepsy, that respond poorly or incompletely to standard treatments. ${ }^{3}$ Liow et al. ${ }^{4}$ surveyed 228 adult patients with epilepsy in the U.S. Midwest about their use of, perception of, and attitudes toward CAM therapies. Of these, $39 \%$ reported using CAM therapies, and $25 \%$ reported use specifically for seizure control. The most common forms of CAM were herbal therapies and other dietary supplements, prayer and spirituality, megavitamins (i.e., high-dose vitamins), chiropractic care, and stress management.

Other surveys in the United States or the United Kingdom suggest that up to one in three patients with epilepsy take herbal therapies, dietary supplements, or both, and that the majority do not inform their treating physicians $^{5-7}$; this includes, for example, persons of South Asian origin living in the United Kingdom. ${ }^{8}$ In one survey, the most frequently used were ginseng (Panax and Eleutherococcus species; less often, Withania species), St. John's wort (Hypericum perforatum), melatonin, ginkgo (Ginkgo biloba), garlic (Allium sativum), and black cohosh (Actaea racemosa). ${ }^{6}$ In another study, garlic, ginkgo, soy (Glycine max), melatonin, and kava (Piper methysticum) were most often taken. ${ }^{7}$ Ginkgo is commonly taken by nursing home residents, including those with epilepsy, and the potential for proconvulsant effects of ginkgo products is cause for concern. ${ }^{9-11}$

Clinical experience suggests that patients may try some herbal therapies in order to reduce AED-related adverse effects or comorbid conditions, such as valerian for insomnia, St. John's wort for depression, or ginkgo for memory disturbance. By inquiring whether patients are taking herbal therapies, physicians may gain insight into nonseizure-related problems that patients may be experiencing.

Developing countries. Herbal therapies for epilepsy in developing countries have evolved over the centuries, often in conjunction with changing cultural beliefs, systems of health care, and levels of education. ${ }^{12,13}$ For example, nearly $40 \%$ of persons responding to a 1988 survey in China would suggest that a friend with epilepsy ask for an herbal medicine doctor or seek acupuncture. ${ }^{14}$ Herbal therapies in developing countries are generally available from traditional healers or practitioners, whether instead of or in addition to medications prescribed by Western-trained physicians. It is not unusual in some regions for herbal therapies to be taken together with AEDs, ${ }^{15}$ with combinations that can be tested experimentally in laboratory animals, ${ }^{16}$ or after treatments prescribed by physicians fail to control seizures. ${ }^{17}$

\section{Regulatory aspects}

Governmental regulations concerning herbal therapies vary around the world. In the United States, prescription drugs are federally regulated by the Food, Drug, and Cosmetic Act, but herbal therapies by the 1994 Dietary Supplement and Health Education Act (DSHEA), under the auspices of the FDA's Office of Nutritional Products, Labeling, and Dietary Supplements, which is also responsible for developing policies for dietary supplements. DSHEA defines a dietary supplement as a product taken by mouth that contains a dietary ingredient intended to supplement the diet. The dietary ingredients in these products may include vitamins, minerals, herbs or other botanicals, amino acids, and substances such as enzymes, organ or glandular tissues, and extracts, concentrates, and metabolites (Overview of dietary supplements, Jan. 3, 2001: http://www.cfsan.fda.gov/ dms/dsoview.html).

Under U.S. law, manufacturers of herbal therapies are responsible for the truthfulness of claims made on product labels and for controlling the quality of their products and verifying their safety. Manufacturers cannot claim effectiveness for a specific medical condition, such as epilepsy, but may claim an effect on a bodily part or function when the claim is accompanied by the following words: "This statement has not been evaluated by the FDA. This product is not intended to diagnose, treat, cure, or prevent any disease."

Under DSHEA, no government agency is required to verify the labeling claims of dietary supplements or to assess their quality and safety. Furthermore, dietary supplements, including herbal therapies, are not required to be produced according to standards of good manufacturing practices (GMP), which is the legal requirement for pharmaceutical products. Consequently, herbal therapies could potentially be contaminated, for example, with microorganisms or pesticides, or could contain potentially toxic levels of heavy metals, as has been documented for some Ayurvedic products, ${ }^{18}$ or could be adulterated with other herbs or drugs. ${ }^{19}$ In addition, the purity and amount of herbal extract or standardized presumed active ingredient per unit may vary significantly within the same bottle or from batch to batch, or from one branded herbal therapy product to another, because of variable manufacturing processes. Patients and many of their treating physicians are generally unaware of the potential for wide variability in purity and in per-dose quantity of herbal therapies.

Two recent developments are changing the role of the FDA role in overseeing the manufacturing and labeling of herbal therapies. First, in June 2007 the FDA issued a final rule, "Current Good Manufacturing Prac- 
tice in Manufacturing, Packaging, Labeling, or Holding Operations for Dietary Supplements" (http://www.fda. gov/ohrms/dockets/98fr/cf0441.pdf), which significantly tightens manufacturing standards for dietary supplements, including herbal therapies, thereby ensuring their quality. Second, the FDA established a process to evaluate the safety and efficacy of herbal therapies (which they refer to as botanical drug products) in mitigating, treating, curing, or diagnosing a disease, which could potentially lead to FDA approval of herbal therapies for specific medical indications, including epilepsy. The first FDA approval of an herbal therapy under the new guidelines was, in late 2006, for an extract of green tea as a topical treatment of genital warts caused by the human papillomavirus (Verigen; http://www.fda.gov/cder/rdmt/ InternetNME06.htm).

\section{Safety issues}

Despite generally being regarded as natural and therefore judged to be safe by the public, herbal therapies, like pharmaceuticals, may cause serious or life-threatening adverse effects ${ }^{20}$; furthermore, the long-term safety profile of most herbal therapies is unknown. ${ }^{21,22}$ Numerous herbal therapies have been anecdotally reported to cause seizures, including in patients with epilepsy ${ }^{23}$; these include anisatin (a component of Japanese star anise, or Ilicium anisatum), which is used in Spain and other countries to treat infant colic, ${ }^{24,25}$ ginkgo nuts, ${ }^{26}$ essential oils, ${ }^{27}$ evening primrose (Oenothera species) and borage (Borago officinalis), ${ }^{27}$ and the stimulant ephedra (ma huang, or Ephedra sinica). ${ }^{28}$ The extract of star fruit (Averrhoa carambola) may cause seizures in uremic patients ${ }^{29}$; it is used to induce seizures experimentally, ${ }^{30}$ as is the extract from Catha edulis (khat), whose fresh young leaves are used recreationally by an estimated 5 million people in eastern Africa and the Arabian Peninsula. ${ }^{31}$ Likewise, an extract of a Chinese herbal therapy for schizophrenia (Coriaria lactone, which is made from the active parts of the plant Loranthus on coriaria sinica Maxim) is the basis of a rat model for pharmacoresistant temporal lobe epilepsy. ${ }^{32}$

The pharmacokinetic interactions between herbal therapies and drugs, including AEDs, have been inadequately studied. Available evidence suggests that St. John's wort, ${ }^{33}$ garlic, echinacea (various Echinacea species), pine bark extract (Pinus pinaster; also known as pycnogel, Pygenol, or Pycnogenol), milk thistle (Silybum species), American hellebore (Veratrum viride), ginkgo, ${ }^{10,11}$ mugwort (Artemisia species), and pipsissewa (Chimaphila umbellata) affect the cytochrome P450 system and could therefore potentially affect serum concentrations of hepatically metabolized AEDs, ${ }^{21-34}$ perhaps with fatal consequences. ${ }^{10}$

\section{Herbal therapies for epilepsy}

Historical evidence suggests that herbal therapies were used to treat convulsive seizures as early as $6000 \mathrm{BC}$ in India, with the origin of Ayurveda, ${ }^{35}$ and $3000 \mathrm{BC}$ in China and in Peru; similarly, Africa and South America have rich traditions in herbal therapies, including for convulsions. ${ }^{36-38}$

The Ayurvedic literature contains treatises on epilepsy-like symptoms, causes, recognition, and treatment. Herbal and dietary therapies, which are recommended for external application, internal use, and topical use in the eyes and nose, include Brahmirasayan, Brahmighritham, Ashwagandha, old pure desi ghee, daily fresh juice of brahmi (Centella asiatica or Bacopa species, among others) with honey, garlic juice in oil, and powdered root of wild asparagus (Asparagus racemosus) with milk. Others are Acacia nilotica (syn. Acacia arabica), Acorus calamus, Bacopa monnieri, Clitorea ternatea, Celastrus paniculatus, Convolvulus pluricaulis, Phyllanthus emblica (syn. Emblica officinalis), mukta pishti (processed from pearls of Mytilus magaritiferus mussels), Withania somnifera. ${ }^{39}$ Recent scientific publications provide the scientific rationale for proceeding with controlled trials of some of these herbal therapies in patients with epilepsy. ${ }^{40,41}$

The oldest Chinese document on epilepsy, The Yellow Emperor's Classic of Internal Medicine, Huang Di Nei Jing, dates in its earliest editions from 770 to $221 \mathrm{BC}^{42}$ Herbal therapies used to treat convulsive diseases in Asia in modern times include Chai-Hu-Long-Ku-Mu-Li-Tan (TW-001), a mixture of extracts from 13 herbal therapies; Gastrodia elata (Tian Ma; gastrodia root); Uncaria rhynchophylla (cat's claw); Menispermum dauricum (moonseed); Shitei-To, a mixture of extracts from three medicinal herbs, Shitei (kaki calyx; the calyx of Diospyros kaki persimmon), Shokyo (gingerroot; rhizome of Zingiber officinale), and Choji (clove; pharmaceutical name, caryophylli flos; the flowerbud of Syzygium aromaticum); mixture of radish (Raphanus sativus) and pepper (Piper species, containing the alkaloid piperine); Qingyangshen (root of Cynanchum otophyllum); Kanbaku-taiso-to, a mixture of three herbal drugs, glycyrrhizae radix (licorice root; Glycyrrhiza species), tritici semen (wheat seed; Triticum aestivum), and zizyphi fructus (spiny jujube fruit; Ziziphus spinosa); paeoniae radix (peony root; Paeonia lactiflora, synonym P. albiflora); and Zheng Tai instant powder (a complex prescription of traditional Chinese medicines used for tonic-clonic seizures). ${ }^{43}$ Several of these herbal therapies have been shown to have neuroprotective properties, ${ }^{4-46}$ efficacy in animal models of epilepsy ${ }^{47-49}$ and hippocampal slice models, ${ }^{50}$ and effects on gene expression. ${ }^{51}$ These studies generally do not specify, however, the methods used to 1) authenticate the source plants, 2) produce extracts 
and fractions, 3) characterize the active ingredients, or 4) perform the preclinical evaluations. ${ }^{43}$

Recent investigations have addressed these limitations. For example, in their study of an extract of Bacopa monnieri, a traditional Ayurvedic therapy, on glutamate receptor binding and GRIN1 gene expression (glutamate receptor, ionotropic, $N$-methyl-D-aspartate 1 gene; previously NMDARI) in the hippocampus of rats after pilocarpine-induced seizures, Khan et al. ${ }^{52}$ describe the source of the plant material, as well as the authentication and extraction methods. Furthermore, voucher specimens of the plant materials were prepared and stored, allowing for further characterization and replication of the findings.

In 2005, a comprehensive literature search identified 3 randomized controlled trials, 5 nonrandomized controlled trials, 6 case-control studies and 57 observational studies, including case reports, of herbal therapies from the East Asia for the treatment of epilepsy. ${ }^{53}$ More than 135 different herbal extracts were used individually or in various combinations (formulas) in these studies, although rarely was the same herbal formula used in more than one study. The most frequently used plant (or animal) extracts were from the species Pinellia ternata (Ban Xia), Arisaema serratum (synonym A. japonicum; Tian Nan Xing), Acorus calamus (Shi Chang Pu), Gastrodia elata (Tian Ma), Buthus martensii (Quan Xie; bark scorpion), Wolfiporia extensa (synonym Poria cocos; $\mathrm{Fu}$ Ling), Bombyx mori (Jiang Qiang; silkmoth; the pharmaceutical name, bombyx batryticatus, indicates silkmoth infestation with a particular fungus), Citrus reticulata (Chen Pi), Uncaria rhynchophylla (Gou Teng), Glycyrrhiza glabra (Gan Cao), and Salvia miltiorrhiza (Dan Shen), as well as Scolopendra subspinipes (centipede), Bupleurum falcatum, Succinum (processed amber), Paeonia lactifolia (synonym P. albiflora), Panax ginseng, Perichaeta communissma (earthworm), and Curcuma longa. ${ }^{43}$ The clinical studies were generally limited by methodological issues in study design, inadequate powering, insufficient categorization of seizure types and epilepsy syndromes, questionable choices of outcome measures and statistical methods, and lack of characterization of the herbal extracts. Only one clinical epilepsy study of an herbal extract has been published since 2005 in the English literature. ${ }^{54}$

\section{Harvard epilepsy botanical program}

Although properly controlled clinical evidence to support the use of specific herbal therapies for patients with epilepsy is lacking, available anecdotal and laboratorybased evidence suggests that further evaluation is warranted. Therefore, a program was established at Harvard Medical School to support preclinical evaluation of herbal therapies for epilepsy. The goals of the program are 1) to identify herbal therapies and compounds iso- lated from them that have promising activity in animal epilepsy models and relevant in vitro assays, 2) to conduct the preclinical studies necessary to proceed with early stage clinical studies, and 3) to plan and initiate these clinical studies.

In pursuit of these goals, collaborations were established with herbal experts and natural product chemists in East Asia, South America, and Africa, in order to 1) identify herbal therapies for evaluation (based on clinical recommendations of herbal experts, electronic database searches, review of original text references, and published results of laboratory or clinical studies) and 2) to test crude extracts and selected fractions of these herbal therapies, as well as pure compounds isolated from those fractions, in well-validated animal models of epilepsy and in vitro assays.

Although the most common reasons for selecting herbal therapies for preclinical evaluation have been either a tradition of use for seizures or known mechanisms of action that are relevant to epilepsy, epidemiological observations may also be helpful. For example, Salih and Mustafa $^{55}$ reasoned that the lower prevalence of epilepsy among school children of Khartoum province, Sudan, compared with that in Europe and North America may be related to frequent dietary ingestion of broad beans (Vicia faba). The authors therefore prepared an extract of Vicia faba and found that it blocked seizures in a mouse strychnine model.

To date, more than 30 herbal extracts and extractderived compounds isolated from Chinese, Japanese, and Indian herbal therapies have been studied by the Harvard program in animal models of epilepsy through the $\mathrm{Na}-$ tional Institute of Neurological Disorders and Stroke (NIH-NINDS) Anticonvulsant Screening Project (ASP), and many have also been evaluated using in vitro assays of neuronal receptor or ion channel function. Approximately two-thirds of these extracts and extract-derived compounds show activity in vitro, in vivo, or both. An example is huperzine A.

Huperzine A. Based on its proposed action as a noncompetitive NMDA receptor antagonist, ${ }^{56}$ huperzine A was selected for further evaluation as a potential anticonvulsant. Huperzine A is a sesquiterpene lycopodium alkaloid, typically isolated from Chinese club moss (Huperzia serrata); in Chinese folk medicine it is known as qian ceng ta. The chemical name for huperzine $\mathrm{A}$ is $[5 R-(5 \alpha, 9 \beta, 11 E)]-5$-amino-11-ethylidene-5,6,9, 10-tetrahydro-7-methyl-5,9-methanocycloocta[b]pyridin$2(1 \mathrm{H})$-one. The molecular formula is $\mathrm{C}_{15} \mathrm{H}_{18} \mathrm{~N}_{2} \mathrm{O}$, and the molecular weight is 242.32 .

Huperzine A has been traditionally used in China for the treatment of swelling, fever and inflammation, blood disorders, and schizophrenia, ${ }^{57}$ and it is currently used in China for Alzheimer's disease. Huperzine A was classified as a dietary supplement by the FDA in 1997. It is 
available in health food stores or via the Internet, labeled as a memory aid, and was recently studied in a multicenter NIH-sponsored trial for Alzheimer's disease at dosages up to $400 \mu \mathrm{g}$ b.i.d. (http://clinicaltrials.gov/ct/ show/NCT00083590?order $=9$; accessed December 17, 2008).

Huperzine A (ADD 357133) was submitted to the ASP and found to be potently active against subcutaneously administered pentylenetetrazol-induced seizures and less so against maximal electroshock-induced seizures after oral administration to Swiss-Webster mice, with peak anticonvulsant activity at 1 hour. ${ }^{58}$ At doses of 1,2 , and $4 \mathrm{mg} / \mathrm{kg}$, a maximum of $62.5 \%$ protection was observed. Impairment on the rotarod test was observed in 75 and $100 \%$ of mice tested at doses of 2 and $4 \mathrm{mg} / \mathrm{kg}$, respectively. The $\mathrm{TD}_{50}$ was $0.83 \mathrm{mg} / \mathrm{kg}$.

In the $6-\mathrm{Hz}$ model, $\mathrm{ED}_{50}$ values for intraperitoneal huperzine A were $0.28,0.34$ and $0.78 \mathrm{mg} / \mathrm{kg}$ for 22,32 , and $44 \mathrm{~mA}$, respectively, suggesting a possible advantage over phenytoin, carbamazepine, lamotrigine and topiramate, each of which display limited efficacy in this model at doses devoid of behavioral toxicity. ${ }^{59}$ The less than twofold ratio of dosages effective across the range of current strengths suggests a further possible advantage over other drugs that are active in this model, such as levetiracetam.

\section{SUMMARY}

Despite the widespread use of herbal therapies by patients with epilepsy, there is a striking lack of controlled evidence to support their use, and anecdotal reports suggest that some herbal therapies may pose a safety risk to this population. Absence of proof, however, is not necessarily proof of absence, and the centuries-old traditions of use of herbal therapies for epilepsy provide a reasonable basis for systematically proceeding with preclinical assessments using modern scientific methods. Indeed, preclinical work at Harvard and elsewhere based on this approach suggests that the study of herbal therapies and herbal-derived compounds may yield promising candidates for further clinical development.

Herbal therapies may, therefore, potentially yield new treatment options for patients whose seizures are uncontrolled despite available AEDs, and may also represent inexpensive, culturally acceptable treatments for the millions of people around the world with untreated epilepsy.

Acknowledgments: This work was supported by grants from the Epilepsy Therapy Project, the Epilepsy Research Foundation, and the American Epilepsy Society.

\section{REFERENCES}

1. Brodie MJ. Diagnosing and predicting refractory epilepsy. Acta Neurol Scand Suppl 2005;181:36-39.
2. Meinardi H, Scott RA, Reis R, Sander JW; ILAE Commission on the Developing World. The treatment gap in epilepsy: the current situation and ways forward. Epilepsia 2001;42:136-149.

3. Wahner-Roedler DL, Elkin PL, Vincent A, et al. Use of complementary and alternative medical therapies by patients referred to a fibromyalgia treatment program at a tertiary care center. Mayo Clin Proc 2005;80:55-60.

4. Liow K, Ablah E, Nguyen JC, et al. Pattern and frequency of use of complementary and alternative medicine among patients with epilepsy in the midwestern United States. Epilepsy Behav 2007; 10:576-582.

5. Easterford K, Clough P, Comish S, Lawton L, Duncan S. The use of complementary medicines and alternative practitioners in a cohort of patients with epilepsy. Epilepsy Behav 2005;6:59-62.

6. Peebles CT, McAuley JW, Roach J, Moore JL, Reeves AL. Alternative medicine use by patients with epilepsy. Epilepsy Behav 2000;1:74-77.

7. Sirven JI, Drazkowski JF, Zimmerman RS, Bortz JJ, Shulman DL, Macleish M. Complementary/alternative medicine for epilepsy in Arizona. Neurology 2003;61:576-577.

8. Rhodes PJ, Small N, Ismail H, Wright JP. The use of biomedicine, complementary and alternative medicine, and ethnomedicine for the treatment of epilepsy among people of South Asian origin in the UK. BMC Complement Altern Med 2008;8:7.

9. Harms SL, Garrard J, Schwinghammer P, Eberly LE, Chang Y, Leppik IE. Ginkgo biloba use in nursing home elderly with epilepsy or seizure disorder. Epilepsia 2006;47:323-329.

10. Kupiec T, Raj V. Fatal seizures due to potential herb-drug interactions with Ginkgo biloba. J Anal Toxicol 2005;29:755-758.

11. Bressler R. Herb-drug interactions between Ginkgo biloba and prescription medications. Geriatrics 2005;60:30-33.

12. Elferink JGR. Epilepsy and its treatment in the ancient cultures of America. Epilepsia 1999;40:1041-1046.

13. Kim IJ, Kang JK, Lee SA. Factors contributing to the use of complementary and alternative medicine by people with epilepsy. Epilepsy Behav 2006;8:620-624.

14. Lai CW, Huang X, Lai YHC, Zhang Z, Liu G, Yang MZ. A survey of public awareness, understanding and attitudes toward epilepsy in Henan province, China. Epilepsia 1990;31:182-187.

15. Danesi MA, Adetunji JB. Use of alternative medicine by patients with epilepsy: a survey of 265 epileptic patients in a developing country. Epilepsia 1994;35:344-351.

16. Vattanajun A, Watanabe H, Tantisira MH, Tantisira B. Isobolographically additive anticonvulsant activity between Centella asiatica's ethyl acetate fraction and some antiepileptic drugs. J Med Assoc Thai 2005;88 Suppl 3:S131-S140.

17. Tandon M, Prabhakar S, Pandhi P. Pattern of use of complementary/alternative medicine (CAM) in epileptic patients in a tertiary care hospital in India. Pharmacoepidemiol Drug Saf 2002;11:457463.

18. Saper RB, Kales SN, Paquin J, et al. Heavy metal content of Ayurvedic herbal medicine products. JAMA 2004;292:28682873.

19. Huang WF, Wen KC, Hsiao ML. Adulteration by synthetic therapeutic substances of traditional Chinese medicines in Taiwan. J Clin Pharmacol 1997;37:344-350.

20. Ernst E. Serious psychiatric and neurological adverse effects of herbal medicine: a systematic review. Acta Psychiatr Scand 2003; 108:83-91.

21. Pearl PL, Robbins EL, Bennett HD, Conry JA. Use of complementary and alternative therapies in epilepsy: cause for concern. Arch Neurol 2005;62:1472-1475.

22. Huxtable RJ. The harmful potential of herbal and other plant products. Drug Saf 1990;5 Suppl 1:126-136.

23. Luciano DJ, Spinella M. Herbal treatment of epilepsy: phytotherapy. In: Devinsky O, Schachter SC, Pacia S, editors. Complementary and alternative therapies for epilepsy. New York: Demos Medical Publishing, 2005:143-155.

24. Gil Campos M, Pérez Navero JL, Ibarra De La Rosa I. Convulsive status secondary to star anise poisoning in a neonate [In Spanish]. An Esp Pediatr 2002;57:366-368.

25. Johanns ES, van der Kolk LE, van Gemert HM, Sijben AE, Peters $\mathrm{PW}$, de Vries I. An epidemic of epileptic seizures after consump- 
tion of herbal tea [In Dutch]. Ned Tijdschr Geneeskd 2002;146:813-816.

26. Miwa H, Iijima M, Tanaka S, Mizuno Y. Generalized convulsions after consuming a large amount of gingko nuts. Epilepsia 2001; 42:280-281.

27. Spinella M. Herbal medicines and epilepsy: the potential for benefit and adverse effects. Epilepsy Behav 2001;2:524-532.

28. Sirven JI. Alternative therapies for seizures: promises and dangers. Semin Neurol 2007;27:325-330.

29. Neto MM, Cardeal da Costa JA, Garcia-Cairasco N, Netto JC, Nakagawa B, Dantas M. Intoxication by star fruit (Averrhoa carambola) in 32 uraemic patients: treatment and outcome. Nephrol Dial Transplant 2003;18:120-125.

30. Carolino RO, Beleboni RO, Pizzo AB, et al. Convulsant activity and neurochemical alterations induced by a fraction obtained from fruit Averrhoa carambola (Oxalidaceae: Geraniales). Neurochem Int 2005;46:523-531.

31. Oyungu E, Kioy PG, Patel NB. Proconvulsant effect of khat (Catha edulis) in Sprague dawley rats. J Ethnopharmacol 2009; 121:476-478.

32. Wang Y, Zhou D, Wang B, et al. A kindling model of pharmacoresistant temporal lobe epilepsy in Sprague-Dawley rats induced by Coriaria lactone and its possible mechanism. Epilepsia 2003; 44:475-488.

33. Obach RS. Inhibition of human cytochrome P450 enzymes by constituents of St. John's wort, an herbal preparation used in the treatment of depression. J Pharmacol Exp Ther 2000;294:88-95.

34. Delgoda R, Westlake AC. Herbal interactions involving cytochrome P450 enzymes: a mini review. Toxicol Rev 2004;23:239249.

35. Jain S. Ayurveda: the ancient Indian system of medicine. In: Devinsky O, Schachter SC, Pacia S, editors. Complementary and alternative therapies for epilepsy. New York: Demos Medical Publishing, 2005:123-128.

36. Ojewole JA. Anticonvulsant property of Sutherlandia frutescens R. BR. (variety Incana E. MEY.) [Fabaceae] shoot aqueous extract. Brain Res Bull 2008;75:126-132.

37. Ojewole JA. Anticonvulsant activity of Hypoxis hemerocallidea Fisch. \& C. A. Mey. (Hypoxidaceae) corm ('African potato') aqueous extract in mice. Phytother Res 2008;22:91-96.

38. Mahomed IM, Ojewole JA. Anticonvulsant activity of Harpagophytum procumbens DC [Pedaliaceae] secondary root aqueous extract in mice. Brain Res Bull 2006;69:57-62.

39. Chauhan AK, Dobhal MP, Joshi BC. A review of medicinal plants showing anticonvulsant activity. J Ethnopharmacol 1988; 22:11-23.

40. Kasture VS, Deshmukh VK, Chopde CT. Anxiolytic and anticonvulsive activity of Sesbania grandiflora leaves in experimental animals. Phytother Res 2002;16:455-460.

41. Kulkarni SK, Akula KK, Dhir A. Effect of Withania somnifera Dunal root extract against pentylenetetrazol seizure threshold in mice: possible involvement of GABAergic system. Indian J Exp Biol 2008;46:465-469.

42. Lai CW, Lai YH. History of epilepsy in Chinese traditional medicine. Epilepsia 1991;32:299-302.

43. Schachter SC, Acevedo C, Acevedo KA, et al. Complementary and alternative medical therapies. In: Engel J, Pedley TA, editors. Epilepsy: a comprehensive textbook. 2nd ed. Philadelphia: Wolters Kluwer Health/Lippincott Williams \& Wilkins, 2008:1407-1414.
44. Kim HJ, Moon KD, Oh SY, Kim SP, Lee SR. Ether fraction of methanol extracts of Gastrodia elata, a traditional medicinal herb, protects against kainic acid-induced neuronal damage in the mouse hippocampus. Neurosci Lett 2001;314:65-68.

45. Hsieh CL, Tang NY, Chiang SY, Hsieh CT, Lin JG. Anticonvulsive and free radical scavenging actions of two herbs, Uncaria rhynchophylla (MIQ) Jack and Gastrodia elata B1., in kainic acidtreated rats. Life Sci 1999;65:2071-2082.

46. Hsieh CL, Chang CH, Chiang SY, et al. Anticonvulsive and free radical scavenging activities of vanillyl alcohol in ferric chlorideinduced epileptic seizures in Sprague-Dawley rats. Life Sci 2000; 67:1185-1195.

47. Chiou LC, Ling JY, Chang CC. Chinese herb constituent $\beta$-eudesmol alleviated the electroshock seizures in mice and electrographic seizures in rat hippocampal slices. Neurosci Lett 1997;231:171174.

48. Hsieh CL, Chen MF, Li TC, et al. Anticonvulsant effect of Uncaria rhynchophylla (Miq) Jack. in rats with kainic acid-induced epileptic seizure. Am J Chin Med 1999;27:257-264.

49. Minami E, Shibata H, Nunoura Y, Nomoto M, Fukuda T. Efficacy of shitei-to, a traditional Chinese medicine formulation, against convulsions in mice. Am J Chin Med 1999;27:107-115.

50. Ameri A, Gleitz J, Peters T. Bicuculline-induced epileptiform activity in rat hippocampal slices: suppression by aconitum alkaloids. Planta Med 1997;63:228-232.

51. Sugaya E, Yuyama N, Kajiwara K, et al. Regulation of gene expression by herbal medicines: a new paradigm of gene therapy for multifocal abnormalities of genes. Res Commun Mol Pathol Pharmacol 1999;106:171-180.

52. Khan R, Krishnakumar A, Paulose CS. Decreased glutamate receptor binding and NMDA R1 gene expression in the hippocampus of pilocarpine induced epileptic rats: neuroprotective role of $\mathrm{Ba}$ copa monnieri extract. Epilepsy Behav 2008;12:54-60.

53. Park J, Wei H, Lawhon D, Schachter SC. Herbal formulas in epilepsy: a systematic review. Epilepsia 2005;46 Suppl 8:215 (abstract).

54. Hijikata Y, Yasuhara A, Yoshida Y, Sento S. Traditional Chinese medicine treatment of epilepsy. J Altern Complement Med 2006; 12:673-677.

55. Salih MA, Mustafa AA. A substance in broad beans (Vicia faba) is protective against experimentally induced convulsions in mice. Epilepsy Behav 2008;12:25-29.

56. Zhang YH, Zhao XY, Chen XQ, Wang Y, Yang HH, Hu GY. Spermidine antagonizes the inhibitory effect of huperzine A on $[3 \mathrm{H}]$ dizocilpine (MK-801) binding in synaptic membrane of rat cerebral cortex. Neurosci Lett 2002;319:107-110.

57. Zangara A. The psychopharmacology of huperzine A: an alkaloid with cognitive enhancing and neuroprotective properties of interest in the treatment of Alzheimer's disease. Pharmacol Biochem Behav 2003;75:675-686.

58. White HS, Schachter S, Lee D, Xiaoshen J, Eisenberg D. Anticonvulsant activity of huperzine $\mathrm{A}$, an alkaloid extract of Chinese club moss (Huperzia serrata). Epilepsia 2005;46 Suppl 8:220 (abstract).

59. Schachter SC, White HS, Murphree LJ, Stables J Huperzine A. In: Bialer M, Johannessen SI, Kupferberg HJ, Levy RH, Perucca E, Tomson T, editors. Progress report on new antiepileptic drugs: a summary of the Eighth Eilat Conference (EILAT VIII). Epilepsy Res 2007;73:10-11. 